\title{
A Comparative Study of Exclusive Breastfeeding Practices Among Working and Non-Working Women in Bharatpur-Tandi, Chitwan, Nepal
}

\author{
Sabina Duwadi ${ }^{1}$ and Hari Prasad Upadhyay ${ }^{2 *}$
}

Submitted: 20 January 2018; Accepted: 18 July 2018

Published online: 26 September 2018

DOI: http://dx.doi.org/10.3126/njs.v2i0.21151

\begin{abstract}
Background: Breastfeeding has been accepted as the most vital intervention for reducing infant mortality, ensuring optimal growth and development of children. Twenty-two percent of newborn deaths can be prevented through breastfeeding in the first hour of birth.

Objective: The objective is to find the proportion of exclusive breastfeeding practices among working and non-working women and significant factors associated with exclusive breastfeeding practices. Exclusive breastfeeding means a baby receives only breast milk without any additional food or drinks, including water until 6 months of age.

Materials and Methods: Semi-structured schedule was adopted to take the information from the respondents. The sample size of the study was 140 of which 70 working and 70 non-working women were selected purposively.

Results: The percentage of exclusive breastfeeding practices among working women was $67.10 \%$ and $81.4 \%$ among non-working women. More than $90 \%$ of the women knew the importance of breastfeeding. Similarly, $68.9 \%$ of working and $67.7 \%$ of the non-working women had initiated breastfeeding within one hour of birth. Type of family, number of children, working hour were statistically significant to exclusive breastfeeding practices.

Conclusion: Exclusive breastfeeding practices were quite higher among non-working women compared to working women. In order to improve breastfeeding practices the concerned authority should formulate the provision of child health care center at working places.
\end{abstract}

Keywords: Breastfeeding, breastfeeding practices, comparative study, exclusive breastfeeding, nonworking women, working women.

Address correspondence to the author: College of Medical Sciences, Chitwan, Nepal

E-mail: bscsabina98458@gmail 1; E-mail: hpchalise@gmail.com ${ }^{* 2}$ (Corresponding author email)

Copyright \& License @ Central Department of Statistics, TU, 2018 


\section{INTRODUCTION}

Breastfeeding has been accepted as the most vital intervention for reducing infant mortality, ensuring optimal growth and development of children. Proper breastfeeding provides all essential nutrients for the first 6 months and it is one of the cost-effective intervention for reducing childhood morbidity and mortality. However, despite the demonstrated benefits of breastfeeding, breastfeeding prevalence and duration are still lower than the international recommendations of exclusive breast feeding (EBF) for the first 6 months of life in many developing countries. Every year 57,000 underfive children lose their lives, among which $54 \%$ of death occurs within the first month of life, $22 \%$ of newborn deaths can be prevented through breastfeeding within the first hour of birth. Currently, only $53 \%$ of babies in Nepal are breastfed exclusively until the age of 6 months and 35\% are breastfed within the first hour of birth. At present, $11 \%$ of under-5 year children in Nepal are underweight and $29 \%$ are wasted (Ministry of Health and Population [MOHP] [Nepal], New ERA, and ICF International Inc., 2012). A study of infant feeding practices of mothers in an urban area of Pokhara in Nepal revealed that among 168 mothers interviewed prevalence of breastfeeding was $99.4 \%$ (167). Only $43.5 \%$ of the mothers initiated breastfeeding within one hour of birth and $60.5 \%$ were practicing exclusive breastfeeding at 5 months (Subba et.al., 2007).

In Nepal, infant mortality rate (IMR) is very high which is 46 per 1000 live births per year (NDHS, 2011). Globally, an estimated 1.3 million lives are lost each year due to inadequate exclusive breast feeding. Less than $35 \%$ of infants worldwide are exclusively breastfed during the first six months of life. Furthermore, malnutrition is responsible for one-third of the 8.8 million deaths annually among children under five. Over two-third of these deaths are often associated with inappropriate feeding practices such as bottle-feeding. More than $15 \%$ of 24 lakh child deaths could be averted in India by optimal breastfeeding practices. Breastfeeding is the ideal method suited for the physiological and psychological needs of an infant (Ekambaram, Bhat \& Ahamed, 2010). The mother's antibody is in the breast milk provides immunity to infants to protect from different diseases (World Health Organization, 2007).

\section{MATERIALS AND METHODS}

\section{Study design}

The comparative analytical study design was used to find the breastfeeding practices among working and non-working women. 


\section{Population and sample}

The study population was total working and nonworking breastfeeding mothers having children aged between 6 month and 1 year living in Ratnanagar-2 Tandi, Chitwan. Data was collected from $2074 / 05 / 10$ to $2074 / 05 / 24$. To get the estimated sample, firstly all the list of the total female population and child population under 1 year was collected from ward office and Ratnanagar Hospital of Ratnagar2 Tandi, Chitwan. The total female populations were 2600 and child populations under 1 year were 970. In order to meet the sample size for the study, different houses were visited and selected. The mother having the children aged between 6 months to 1 year and also the working and non-working status of mother were identified by obtaining information from them. The willing participants were selected for the study. Out of total population, only 140 participants were selected purposively in which 70 were working and 70 were non-working women. Semi-structured interview schedule was used to collect the information.

\section{Reliability of instrument}

After the question was design, pre-test was done in Bharatpuur-10 by taking $10 \%$ sample size. After the pilot study some questions was modify. The reliability was calculated by using Cronbach's alpha (in SPSS). The value was 0.67 , which shows the acceptable level of reliability of the tool. Research proposal approval was taken from concerned authorities (Institution research committee board, community and respondents).

\section{Data analysis plan}

First of all the data were collected from study area. Data was checked, reviewed and organized for accuracy and completeness before coded. Data were entered into the Epidata Version 3.1 and statistical package for the social sciences (SPSS) 20.0. After double checking the completeness of the data, data were analyzed using SPSS 20.0 in descriptive and inferential statistics. Descriptive statistics of quantitative data was presented by frequency and percentage. In the inferential statistics, Chi-square test was used to find association.

\section{RESULTS}

Results of data analysis is presented in this section. Socio demographic information of the respondents was present in Table 1. Regarding the age of the respondent, in the working group 35 $(50 \%)$ are in 25-30 years age group, followed by $21(30 \%)$ in the age group 20-25 years age, while in the working group, 28 (40\%) respondents are in the age group 25-30 years age, followed by 26 $(37.10 \%)$ in the age group $20-25$. Regarding the type of family, in the working age group $36(51.40 \%)$ 
belonged to nuclear family, while other belonged to joint family. In the non-working age group 37 $(52.90 \%)$ were in the nuclear family and other belonged to joint family.

Table 1. Socio-demographic characteristics of working and non-working women, $n=140$.

\begin{tabular}{|c|c|c|c|c|}
\hline \multirow{2}{*}{$\begin{array}{l}\text { Characteristics } \\
\text { Age }\end{array}$} & \multicolumn{2}{|l|}{ Working women } & \multicolumn{2}{|c|}{ Non-working women } \\
\hline & Frequency & & Frequency & Percent \\
\hline $15-20$ & 1 & 1.40 & 4 & 5.70 \\
\hline $20-25$ & 21 & 30 & 26 & 37.10 \\
\hline $25-30$ & 35 & 50 & 28 & 40 \\
\hline $30-35$ & 12 & 17.10 & 10 & 14.30 \\
\hline $35-40$ & 1 & 1.40 & 2 & 2.90 \\
\hline Mean $\pm S D$ & $26.57 \pm 3.69$ & & $25.60 \pm$ & \\
\hline \multicolumn{5}{|l|}{ Type of family } \\
\hline Nuclear & 36 & 51.40 & 37 & 52.90 \\
\hline Joint & 34 & 48.60 & 33 & 47.10 \\
\hline \multicolumn{5}{|l|}{ Ethnicity } \\
\hline Brahmin & 24 & 34.30 & 21 & 30.00 \\
\hline Newar & 8 & 11.40 & 6 & 8.60 \\
\hline Chhetri & 13 & 18.60 & 11 & 15.70 \\
\hline Gurung/Magar/Tamang & 9 & 12.90 & 11 & 15.70 \\
\hline Others & 16 & 22.90 & 21 & 30.00 \\
\hline \multicolumn{5}{|l|}{ Religion } \\
\hline Hindu & 59 & 84.30 & 60 & 85.70 \\
\hline Buddhist & 8 & 11.40 & 4 & 5.70 \\
\hline Christian & 1 & 1.40 & 4 & 5.70 \\
\hline Muslim & 2 & 2.90 & 2 & 2.90 \\
\hline \multicolumn{5}{|l|}{ Educational status } \\
\hline Literate & 70 & 100.00 & 67 & 95.70 \\
\hline Illiterate & - & - & 3 & 4.30 \\
\hline \multicolumn{5}{|l|}{ Occupation } \\
\hline Business & 32 & 45.70 & & \\
\hline Service & 11 & 15.70 & & \\
\hline Teaching & 22 & 31.40 & & \\
\hline Wage labor & 5 & 7.10 & & Contd....... \\
\hline
\end{tabular}


Monthly income

10000 to 20000

27

38.60

20000 to 30000

30

42.90

30000 to 40000

7

10.00

40000 and above

8.60

Number of children

One

48.60

37

52.90

Two

38.60

25

35.70

Three

10.00

8

11.40

Four and above

2.90

0.00

Age of your last born child

6 to 8 month

24.30

14.30

8 to 10 month

28.60

32.90

10 to 12 month

47.10

52.90

Sex of your last born child

Male

55.70

57.10

Female

31

44.30

40

42.90

ANC checkup

Yes

70

100

100

No

\section{How many times}

One time

1.40

0.00

Two time

1.40

1.40

Three time

7.10

12.90

Four time

31.40

34.30

More than four time

22

58.60

51.40

Place of delivery

Home

2.90

1.40

Hospital

68

97.10

1

98.60

Type of delivery

\begin{tabular}{lrrrr} 
Normal & 52 & 74.30 & 54 & 77.10 \\
Caesarean & 15 & 21.40 & 15 & 21.40 \\
Instrumental & 3 & 4.30 & 1 & 1.40 \\
\hline
\end{tabular}


Regarding the ethinicity in the working age group 24 (34.1\%) were brahmin, 16 (22.9\%) were other caste, followed by chhetri $13(18.6 \%)$, in the nonworking category $21(30 \%)$ were brahmin as well as other caste, followed by 11 (15.7\%) were newar and gurung/magar/tamang. Regarding religion, in the wroking women $59(84.3 \%)$ wer Hindu, followed by $8(11.4 \%)$ were buddhist, while in the nonworking women 60 (85.7\%) were Hindu, followed by 4 (5.7\%) Buddhist and Christian. Regarding education status, all the working women were literate while in the non-working category 67 (95.7\%) were literate and rest of them were illiterate. Regarding occupation level, 32 (45.7\%) respondents were doing business. Regarding the monthly income, 30 (42.9\%) had income NRs. 20000. Regarding the number of children, in working women 34 (48.6\%) have one child, 27 (38.60\%) have two children while in non-working women 37 (52.9\%) have one child. Regarding the ANC checkup, all the working and non-working women check their health during pregnancy. Regarding the number number of times, in working category 41 (58.6\%) visited more than four times, in non-working $36(51.4 \%)$ visited more than four times. Regarding place of delivery 2 (2.9\%) working and 1 (1.4\%) non-working women whad delivery at home while 68 (97.1\%) working and 69 (98.6\%) non-working women delivered in hospital. Regarding the type of delivery, 52 (74.3\%) working and 54 (77.1\%) non-working women had normal delivery, 52 (74.3\%) working and 54 (77.1\%) non-working women had normal delivery, 52 (74.3\%) working and 54 (77.1\%) non-working women had normal delivery.

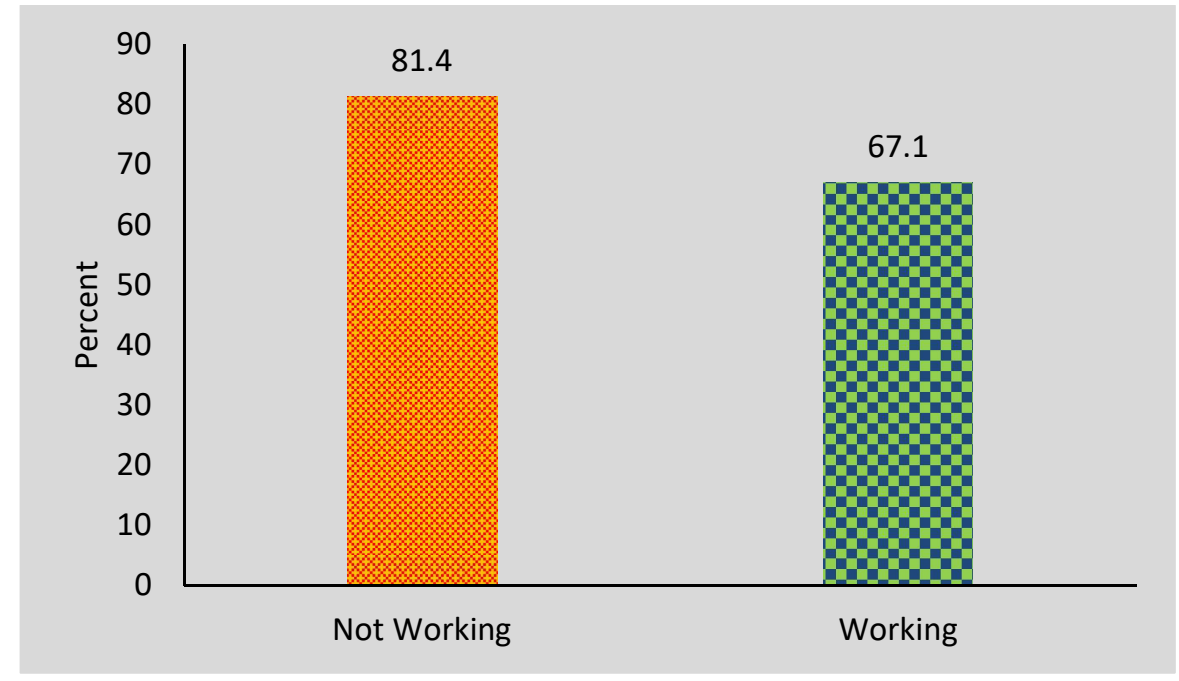

Fig. 1. Percent of exclusive breast feeding among working and non-working mothers, $n=140$.

Percent of exclusive breast feeding among working and non-working mothers are shown in Figure 1. In non-working category, the proportion was $81.4 \%$ and in working category, the proportion was $67.1 \%$. 
Table 2. Factors influencing exclusive breastfeeding among working women, $n=70$.

\begin{tabular}{|c|c|c|c|c|}
\hline \multirow{2}{*}{ Characteristics } & \multicolumn{2}{|c|}{ Working women } & \multirow{2}{*}{ Chi-square } & \multirow{2}{*}{$p$-value } \\
\hline & EBF (\%) & No EBF (\%) & & \\
\hline \multicolumn{5}{|l|}{ Age } \\
\hline$<25$ & $19(40.4)$ & $9(39.1)$ & 0.11 & 0.917 \\
\hline$\geq 25$ & $28(59.6)$ & $14(60.9)$ & & \\
\hline \multicolumn{5}{|l|}{ Type of family } \\
\hline Nuclear & $27(57.4)$ & $9(39.1)$ & & \\
\hline Joint & $20(42.6)$ & $14(60.9)$ & 2.01 & 0.015 \\
\hline \multicolumn{5}{|l|}{ Pre-lacteal* } \\
\hline Yes & $7(14.9)$ & $12(52.2)$ & 10.853 & 0.001 \\
\hline No & $40(58.1)$ & $11(47.82)$ & & \\
\hline \multicolumn{5}{|l|}{ Occupation } \\
\hline Business & $22(59.4)$ & $10(43.5)$ & & \\
\hline Teacher & $7(18.91)$ & $4(17.4)$ & & \\
\hline Service & $13(35.13)$ & $9(39.1)$ & 3.19 & 0.363 \\
\hline Wage & $5(13.51)$ & - & & \\
\hline \multicolumn{5}{|c|}{ Number of children } \\
\hline One & $27(57.4)$ & $7(30.4)$ & & \\
\hline Two & $13(27.6)$ & $14(60.9)$ & & \\
\hline Three & $5(10.7)$ & $2(8.7)$ & 7.7 & 0.045 \\
\hline Four & $2(4.3)$ & - & & \\
\hline \multicolumn{5}{|l|}{ Type of delivery } \\
\hline Normal & $36(78.7)$ & $16(69.6)$ & & \\
\hline Operational & $10(21.2)$ & $5(21.7)$ & 1.65 & 0.43 \\
\hline Instrumental & $1(2.12)$ & $2(8.6)$ & & \\
\hline \multicolumn{5}{|l|}{ Religion } \\
\hline Hindu & $39(83)$ & $20(87.1)$ & & \\
\hline Buddhist & $6(12.8)$ & $2(8.7)$ & 1.009 & 0.739 \\
\hline Muslim & $1(2.1)$ & - & & \\
\hline Christian & $1(2.1)$ & $1(2.1)$ & & \\
\hline \multicolumn{5}{|l|}{ Working hour } \\
\hline 6 hour & $16(34)$ & $10(43.5)$ & & \\
\hline 7 hour & $3(6.4)$ & $2(8.7)$ & 6.33 & 0.034 \\
\hline
\end{tabular}



8 hour
$17(36.2)$
$11(47.8)$
$\geq 9$ hour
$11(23.4)$
Working distance
10 to 13 minutes
$17(73.9)$
13 to 15
$5(10.6)$
$6(26.1)$
3.9
0.139
$\geq 15$
$3(6.4)$
$-$

\section{Mass media**}
Yes
$15(71.4)$
0.856
0.356
No
$6(28.6)$

All $p$-values are compared at 5\% level of significance.

*Pre-lacteal refers to feeding of infant formula, water or sugar, honey, ghee to the child.

**Mass media indicate $\mathrm{FM} / \mathrm{TV} /$ Internet which are used for information regarding breastfeeding.

Association between exclusive breastfeeding among working women with different characteristics are shown in Table 2. Result shows that type of family, pre-lacteal and number of children, working hour are found to be statistically significant $(p$-value $<0.05)$. Association between exclusive breastfeeding among non-working with different characteristics are shown in Table 3. Result shows that type of family, pre-lacteal, education status and number of children are found to be statistically significant ( $p$-value $<0.05)$.

\section{CONCLUSION}

Exclusive breastfeeding practices were quite higher among non-working women than working women. Similarly, majority of the participants knew the importance of breastfeeding practices and more than three fifth participants have initiated breastfeeding within one hour. Type of family, number of children and working hour are found to be statistically significant to exclusive breastfeeding practices. So, different concerning authorities should make the provision of child health care center at working place. Likewise, family members should also involve supporting the mother in feeding the baby optimally to improve the breastfeeding practices. Based on the finding of the study, prevalence of exclusive breastfeeding practices among the working women is less than of non-working women, so the concerned authority should formulate the policy directed towards the working women. Different programs should be conducted to aware the family members about the importance/significance of breastfeeding at different levels. Provision of child health care center at working place should be made so that mother can get time to feed their babies during working hour. Facilities at the workplace should provide privacy to the mother and the mother should be given adequate breaks during her work to feed the baby. The finding of this study will help to assess the prevalence and factors influencing exclusive 
breastfeeding practices among working and non-working women. This work would serve as a reference material for future researchers who intend to carry out researches related to this one in particular.

Table 3. Factors influencing exclusive breastfeeding among not working women, $n=70$

\begin{tabular}{|c|c|c|c|c|}
\hline \multirow{2}{*}{ Characteristics } & \multicolumn{2}{|c|}{ Not Working } & \multirow{2}{*}{ Chi-square } & \multirow{2}{*}{$p$-value } \\
\hline & EBF (\%) & No EBF (\%) & & \\
\hline \multicolumn{5}{|l|}{ Age } \\
\hline$<25$ & $30(52.6)$ & $6(46.2)$ & 0.178 & 0.673 \\
\hline$\geq 25$ & $27(47.4)$ & $7(53.8)$ & & \\
\hline \multicolumn{5}{|l|}{ Type of family } \\
\hline Nuclear & $28(49.1)$ & $9(69.2)$ & 1.71 & 0.019 \\
\hline Joint & $29(50.9)$ & $4(30.8)$ & & \\
\hline \multicolumn{5}{|c|}{ Education status } \\
\hline Literate & $55(96.5)$ & $12(92.3)$ & 9.3 & 0.075 \\
\hline Illiterate & $2(3.5)$ & $1(7.7)$ & & \\
\hline \multicolumn{5}{|l|}{ Pre-lacteal* } \\
\hline Yes & $10(17.5)$ & $10(76.9)$ & 18.289 & $<0.001$ \\
\hline No & $47(82.5)$ & $3(23.1)$ & & \\
\hline \multicolumn{5}{|l|}{ Religion } \\
\hline Hindu & $49(86)$ & $11(84.6)$ & & \\
\hline Buddhist & $3(5.3)$ & $1(7.7)$ & 1.31 & 0.729 \\
\hline Muslim & $3(5.3)$ & $1(7.7)$ & & \\
\hline Christian & $2(3.5)$ & - & & \\
\hline \multicolumn{5}{|c|}{ Number of children } \\
\hline One & $30(52.6)$ & $7(53.8)$ & & \\
\hline Two & $19(33.3)$ & $6(46.2)$ & 2.31 & 0.031 \\
\hline Three & $8(14)$ & - & & \\
\hline \multicolumn{5}{|l|}{ Type of delivery } \\
\hline Normal & $44(77.2)$ & $10(76.9)$ & & \\
\hline Operation & $12(21.1)$ & $3(23.1)$ & 0.28 & 0.883 \\
\hline Instrumental & $1(1.8)$ & - & & \\
\hline
\end{tabular}

All $p$-values are compared at $5 \%$ level of significance.

*Pre-lacteal refers to feeding of infant formula, water or sugar, honey, ghee to the child. 


\section{CONFLICT OF INTEREST}

The author declared that there is no conflict of interest.

\section{REFERENCES}

Ekambaram, M., Bhat, V., \& Ahamed, M. A. P. (2010). Knowledge, attitiude and practice of breastfeeding among postnatal mothers. Current Pediatric Research, 14(2), p119.

Ministry of Health and Population [Nepal], New ERA, and ICF International Inc. (2012). Nepal Demographic and Health Survey 2011. Kathmandu, Nepal.

Subba, S. H., Chandrashekhar, T. S., Binu, V. S., Joshi, H. S., Rana, M. S., \& Dixit, S. B. (2007). Infant feeding practices of mothers in an urban area in Nepal. Kathmandu Univ Med J, 5(1), 42-7.

World Health Organization (2007). Protein and amino acid requirements in human nutrition. World health organization technical report series, (935), 1.

Reference to this paper should be made as follows:

Duwadi, S., \& Upadhyay, H. P. (2018). A comparative study of exclusive breastfeeding practices among working and non-working women in Bharatpur-Tandi, Chitwan, Nepal. Nep. J. Stat., 2, 1-10. 